Article

\title{
Chemical-Mechanical Impact of Nanoparticles and pH Effect of the Slurry on the CMP of the Selective Layer Surfaces
}

\author{
Filip Ilie ${ }^{1, *}$ and George Ipate ${ }^{2}$ \\ 1 Department of Machine Elements and Tribology, Polytechnic University of Bucharest, \\ 313 Spl. Independentei, 060042 Bucharest, Romania \\ 2 Department of Biotechnical Systems, Polytechnic University of Bucharest, 313 Spl. Independentei, \\ 060042 Bucharest, Romania; puiuipate@yahoo.com \\ * Correspondence: ilie.filip@yahoo.com; Tel.: +40-21-402-9411
}

Academic Editor: Costas Charitidis

Received: 29 March 2017; Accepted: 19 May 2017; Published: 23 May 2017

\begin{abstract}
This paper provides a tribochemical study of the selective layer surface by chemical mechanical planarization (CMP). CMP is used to remove excess material obtained in the process of selective transfer. The paper aims at a better understanding of the planarization (polishing) and micromachining. The planarization becomes effective if the material removal rate (MRR) is optimal and the surface defects are minimal. The $\mathrm{pH}$ of the slurry plays a very important role in removing the selective layer by CMP, and hydrogen peroxide $\left(\mathrm{H}_{2} \mathrm{O}_{2}\right)$ is the most common oxidizer used in CMP slurry. The purpose of this paper is the analysis of the $\mathrm{pH}$ effect on the etching rate (ER) and on the behavior of selective layer polishing by a constant concentration of $\mathrm{H}_{2} \mathrm{O}_{2}$ and the influence of nanoparticles size and concentration on selective layer surface CMP. The nanoparticle size used is $250 \mathrm{~nm}$. The MRR results through CMP and ER have been shown to be influenced by the presence of oxides on the selective layer surface and have been found to vary with the slurry $\mathrm{pH}$ at constant $\mathrm{H}_{2} \mathrm{O}_{2}$ concentrations. The CMP slurry plays an important role in the CMP process performance and should be monitored for optimum results and minimal surface defects. The paper analyzes the impact of chemical-mechanical, inter-nanoparticle, and pad-nanoparticle-substrate interactions on CMP performance, taking into account the state of friction at the interface, by measuring the friction force. Selective layer CMP optimization studies were required to control the chemical and mechanical interactions at the interface between the slurry and the selective layer, the slurry chemistry, the properties, and the stability of the suspended abrasive nanoparticles.
\end{abstract}

Keywords: nanoparticle interaction; material removal rate; etching rate; friction at interface; slurry stability; corrosion products

\section{Introduction}

The selective transfer phenomenon takes place in the friction process of two materials and in the presence of specific lubricants by transferring the material from one element of a friction couple to the other. This transfer can be performed safely if there is a favorable energy, a relative movement, and if, in the friction area, is a copper-based material and a suitable lubricant (glycerin or a special lubricant) [1]. Due to the structure formed on the contact surfaces by selective transfer, the friction force is very low $[2,3]$. The predominant element in the selective layer structure is copper. By scanning with an atomic force microscope (AFM) of the selective layer after the chemical mechanical planarization (CMP) process it is found that the surface of the oxide layer is removed at different rates depending on the depth of removal and the $\mathrm{pH}$ of the solution. CMP is a material removal and surface smoothing process, which is possible by the combination of chemical and mechanical interactions [4-9]. 
Although the basic principles of CMP are well known, selective layer CMP remains un-optimized because the mechanism of selective layer removal during planarization (polishing) and the necessary surface chemical processes are still unknown.

To optimize selective layer CMP it is necessary to control the chemical and mechanical interactions at the interface between the slurry and selective layer during the planarization process [4,5]. It will also require a deeper understanding of the material removal rate (MRR) during planarization and a determination of the specific role of each chemical constituent in the slurry [6].

The chemical state of the selective layer surface and the $\mathrm{pH}$ of the slurries play a paramount role in the selective layer CMP removal process. X-ray photoelectron spectroscopy (XPS) is an important surface analytical tool that can be used to identify compounds formed on the metal surface due to the action of chemicals present in the CMP slurry. In the literature, there are numerous studies on similar topics [10-26] applied to the copper CMP of integrated circuits. It is worth mentioning that the present study intends to extend to other fields, namely to surfaces coated through selective transfer (the surfaces of the selective layer) in the friction process, considering the slurry $\mathrm{pH}$ (important for removal through CMP of the selective layer) [7,22-26], $\mathrm{H}_{2} \mathrm{O}_{2}$ (the most common oxidant) [27-33], size [21,28-31], and concentration [12,21,34] of nanoparticles used in the CMP slurry. Thus, this paper explores the $\mathrm{pH}$ effect at a constant $\mathrm{H}_{2} \mathrm{O}_{2}$ concentration on the etching and polishing behavior of the selective layer and the influences on size and concentration of nanoparticles during selective layer surface CMP.

\section{Experimental Details}

Selective layer surface investigations related to the CMP process were carried out on a metal pattern wafer (Workshop of the Department of Machine Elements \& Tribology, Bucharest, Romania) with the selective layer, as there are materials in which under optimum friction conditions, and in the presence of lubricants, the wear phenomenon itself manifests as a transfer of material from one element of the friction pair to the other, a specific selective transfer phenomenon. This is a requirement for any high-efficiency friction couple and a normal process for the self-adjustment phenomenon if there is a favorable energy in the presence of relative movement.

A selective transfer can be achieved in a friction couple if, in the friction area, there is a material consisting of copper alloy (bronze) and the adequate lubricant (glycerin). The metal (steel) pattern wafer with the selective layer was obtained in the friction process between a steel wafer and bronze in the presence of glycerin, when a material transfer takes place from the bronze surface to the steel surface, forming a thin selective layer, in which copper is predominant $(\geq 85 \%)$, with a different structure than copper obtained through normal electrolytic procedures.

The planarization was performed on $25 \mathrm{~mm} \times 25 \mathrm{~mm}$ samples cleaved from a $250 \mathrm{~mm}$ diameter patterned metal wafer with a selective layer (OLC45 steel coated with a selective layer formed in the friction process with CuSn12T bronze). Sample discs coated with a selective layer containing $85 \%$ copper in purity and $25 \mathrm{~mm}$ in diameter were polished with 600 grit sandpaper and thoroughly cleaned with acetone, isopropanol, and distilled water. The specimens were then immersed in $\mathrm{pH}$ buffer solutions with $5.5 \mathrm{vol} \% \mathrm{H}_{2} \mathrm{O}_{2}$ for a certain period of time. Subsequently, XPS examination (PHI-5702 electron spectrometer, ULVAC-PHI.INC., Chigasaki, Japan) and scanning electron microscopy (SEM, AA7000 Scanning Electron Microscope, Angstrom Advanced Inc., Stoughton, MA, USA) was performed.

The polishing experiments were carried out using a CMP tool (UMT TriboLab ${ }^{\mathrm{TM}}$, San Jose, CA, USA): a rotary type polisher CP-4 with perforated, nonwoven pads. The load is uniformly applied to the wafer support using air pressure. In this study, the pressure and polishing linear velocity were maintained constant at $20 \mathrm{kPa}$ and $30 \mathrm{~m} / \mathrm{min}(0.5 \mathrm{~m} / \mathrm{s})$, respectively.

The CMP polisher is equipped with an in situ monitoring system of both friction force (with a piezoelectric force sensor embedded in the polishing head) and temperature. The sensor 
signals were amplified and transferred to a data acquisition system. A thermostat (Carrier ${ }^{\circledR}$-United Technologies, Pittsburg, PA, USA) was used for the temperature control.

The colloidal silica-based slurry for polishing, which contains citric acid as a $\mathrm{pH}$ buffer and an oxidizer $\left(\mathrm{H}_{2} \mathrm{O}_{2}\right)$, was used for the polishing experiments. The colloidal silica concentration of the slurry was maintained constant at $4.5 \mathrm{wt} \%$, and the $\mathrm{pH}$ of the slurry mixture was kept constant at $\mathrm{pH}$. The applied downward pressure was about $0.133 \mathrm{MPa}$. The polishing time was $5 \mathrm{~min}$ and the polishing rate is an average of three independent polishes.

The removal rate was determined by measuring the weight loss of the platen. To prevent agglomeration of the nanoparticles the slurry used was continuously agitated in all polishing tests and directed to the polishing head at a flow rate of $200 \mathrm{~mL} / \mathrm{min}$ and by $10 \mathrm{~mm}$ selective layer wafers.

The chemical elements of the CMP slurry react with the polished wafer surface and form a chemically-modified top layer with properties different from those of the initial wafer surface. For example, passivation of the patterned wafer from a metallic selective layer oxide film prevents the metallic selective layer etching in the low areas, while the high asperities are repeatedly oxidized by the chemicals and abraded by the slurry nanoparticles until the planarization is reached. Consequently, slurry oxidizers provide topographic selectivity during metallic selective layer CMP. In selective layer planarization, the chemical effect is provided by the slurry $\mathrm{pH}$.

The absence of chemically-modified layer is due to the lack of material removed by polishing $[25,34,35]$. It was found that the polishing by chemical means leaves an etched surface with no planarity, whereas polishing only by mechanical means results in a rough surface. Therefore, the formation of a chemically-altered film is necessary to achieve optimal CMP performance.

\section{Results and Discussion}

\subsection{Technological and Technical Issues}

It is essential that, during the CMP process, the superior characteristics of a sample to be polished at a rate higher than that of the lower characteristics leads to a surface planarization. This requires that the pad has to be rigid enough so that it does not deform the supplementary recessed sample areas and the slurry does not etch the lower characteristics during CMP. Thus, the colloidal silica-based acidic slurry (incorporating silica abrasive particles, $\mathrm{H}_{2} \mathrm{O}_{2}$ as an oxidizer, and citric acid as a pH buffer) used here shows an excellent removal effect and a good behavior of planarization.

The CMP slurry abrasive particles provide mechanical action during the polishing process. Hence, the chemically-modified wafer surface layer is abraded continuously by the slurry's abrasive nanoparticles (with nanometric dimensions), which results in material removal. By optimizing the chemical modification and mechanical polishing rates optimal polishing performance can be achieved (minimal deformations and good planarity). The mechanical polishing intensity also varies with the slurry nanoparticle size and concentration, as factors that determine the load applied per nanoparticle. In addition, the mechanical polishing depends on the number of abrasive nanoparticles in the slurry in contact with the wafer surface. These are the very important factors for determining the polishing performance and for understanding the CMP process. Major changes in the nanoparticles-substrate interactions can appear as a result of a variation in the nanoparticle size distribution in the slurry, due to contamination of oversized nanoparticles or loss of the slurry stability $[4,7,17]$. Thus, the MRR response can vary and can be manifested in the poor control process increasing the number of surface deformations, giving birth to micro/nano-scale defects. To check the excellent polishing results observed on selective layer wafers, which are also seen on patterned selective layer samples, the structures were polished with the same slurry used above for selective layer CMP. Thus, Figure 1 shows MRR by CMP and the static ER of the selective layer in slurries with $5.5 \% \mathrm{H}_{2} \mathrm{O}_{2}$ and at different $\mathrm{pH}$ values.

A similar trend of MRRs and ERs with the variation of $\mathrm{pH}$ was observed. Both the selective layer MRR and the ER decreased with the increasing $\mathrm{pH}$ and reach a minimum at $\mathrm{pH} 6.5$, then the removal and etching rates start to increase with increasing $\mathrm{pH}$. 


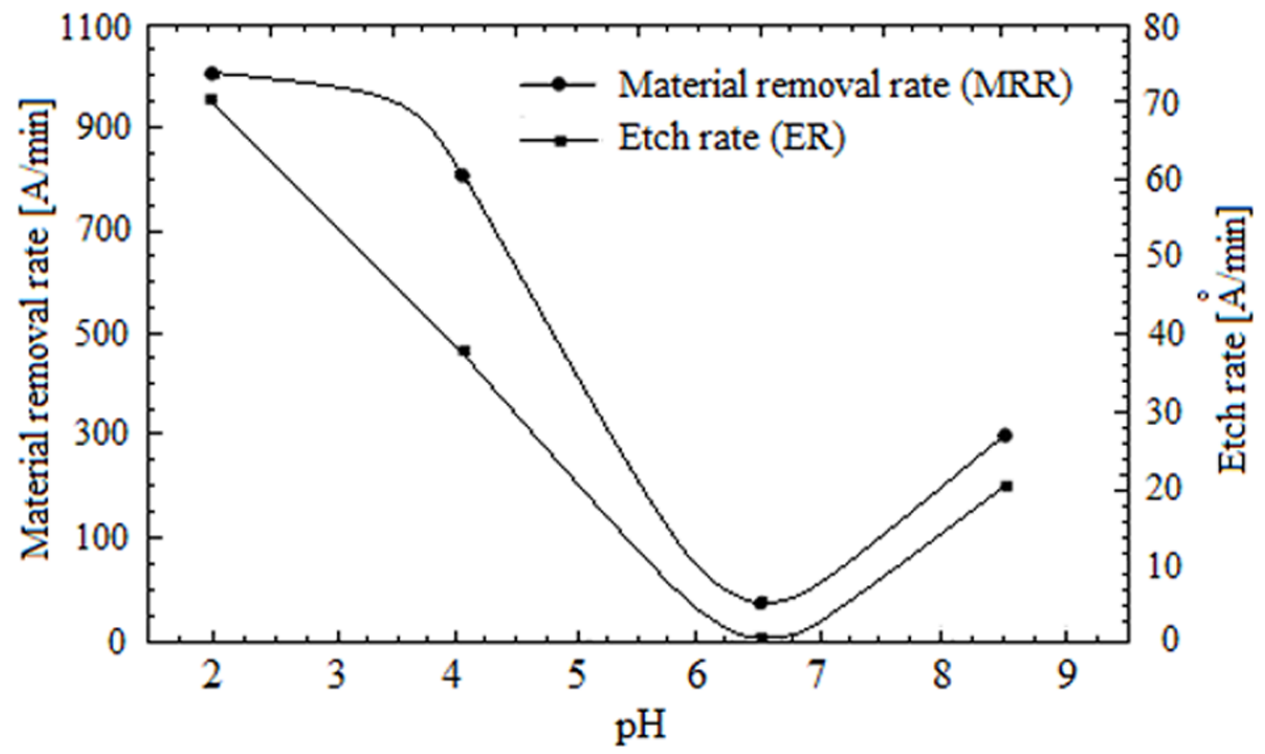

Figure 1. Removal rate and etch rate of selective layer CMP in slurries with $5.5 \% \mathrm{H}_{2} \mathrm{O}_{2}$ at different $\mathrm{pH}$.

\subsection{Effect of the Slurry Nanoparticle Size and Concentration}

Since CMP MRR is dependent on the nanoparticle size and concentration in the slurry, the effects have been investigated by many researchers [26-36]. The reported results are often contradictory and are explained based on the selected ranges of the nanoparticle size and concentration, as well as by their behavior during the CMP process. Thus, the polishing mechanisms depend on the CMP process, as well as on the slurry nanoparticle properties, for a given polishing system.

Two material removal mechanisms were considered to elucidate the observed modifications in polishing rates, which can be explained explicitly on the basis of silicon CMP [24,25,37]. Figure 2 illustrates the MRR obtained with the nanoparticle size of $250 \mathrm{~nm}$ in silica slurry depending on the slurry nanoparticle concentration.

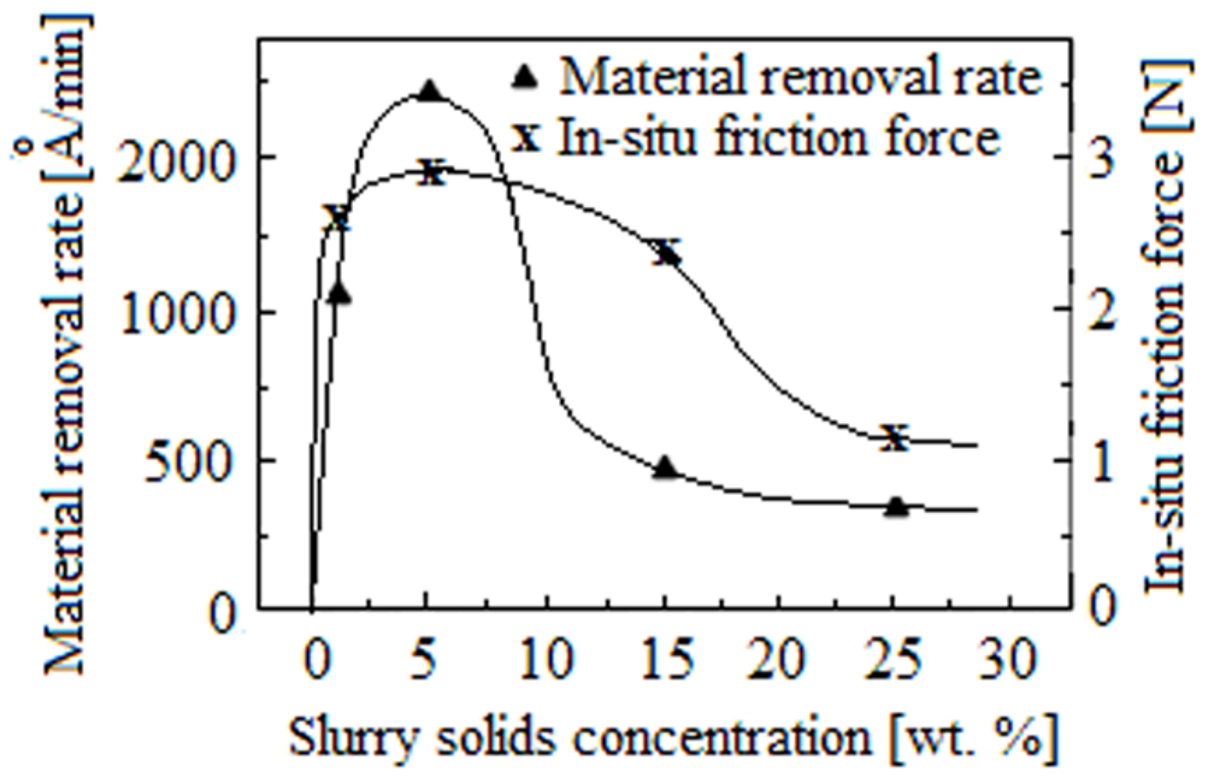

Figure 2. Material removal rate (MRR) and silica friction force, based on a $250 \mathrm{~nm}$ concentration of silicon abrasive nanoparticles. 
At a low nanoparticle concentration in the slurry (from 2.0 to $5.0 \mathrm{wt} \%$ ), MRR increases with the increasing nanoparticles concentration. The wafer surface micrographs are obtained with help of an AFM, and at these concentrations show scratches on the polished wafer surface indicating that the abrasive nanoparticles start rolling and slipping on the wafer surface which results in mechanical removal. MRR reaches a maximum of $5.5 \mathrm{wt} \%$ nanoparticle concentration, after which a significant decrease is detected. This significant decrease is due to the reduction of the load on the nanoparticles with the increase in the number of nanoparticles in the wafer contact area, respective of the changes in the nanoparticle motion.

More nanoparticles tend to start rolling rather than sliding over the wafer surface when the solids concentration increases from 5.0 to $15.0 \mathrm{wt} \%$. As a result, MRR decreases with the increasing solids concentration. Furthermore, surface AFM microphotography at $15.5 \mathrm{wt} \%$ exhibits pitting deformations of the wafer surface faster than scratches, proving that the abrasive nanoparticles are in rolling motion (see Figure 3). Therefore, at these higher solids concentrations, mechanical action is significantly reduced and MRR takes place mainly due to chemical interactions.

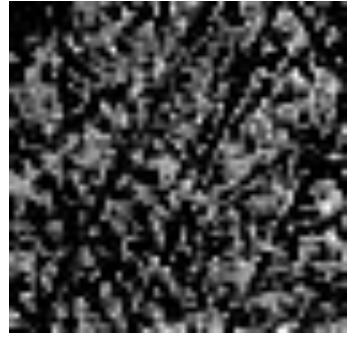

(a)

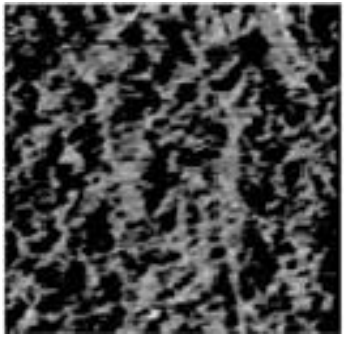

(b)

Figure 3. AFM micrographs at $5.0 \mathrm{wt} \%$ with scratches (a), and at $15.5 \mathrm{wt} \%$ with pitting deformations (b) of the wafer surface.

In support of these mechanisms, in situ friction force measurements conducted on the same principle also show a similar trend in the total friction force depending on the $250 \mathrm{~nm}$ nanoparticle concentration in the slurry (Figure 2). It has also been shown that in situ friction force measurements in the CMP correlate with the MRR in [38-43], i.e., the variation is based on the same considerations (decrease of the load per particle with the increased concentration and start of the nanoparticle rolling motion, which leads to a decrease of the frictional force).

At the same time, it is necessary to reduce the number of surface deformations in the CMP process. For this, it is necessary to act in the contact area by using small-sized nanoparticles at high nanoparticle concentrations. This allows the determination of polishing performance of the slurry. Selective layer samples are immersed and polished in the slurry containing $\mathrm{H}_{2} \mathrm{O}_{2}$ and citric acid at different $\mathrm{pHs}$ and then analyzed using XPS. Surface analysis results of the samples immersed in $5.5 \mathrm{vol} \% \mathrm{H}_{2} \mathrm{O}_{2}$ are shown in Figure 4.

Figure 4a shows the XPS spectra for selective layer copper at $\mathrm{pH} 2,4,6$, and 8 solutions after $30 \mathrm{~min}$ of immersion. The binding energy $(\mathrm{BE})$ value of the $\mathrm{Cu}_{2} \mathrm{O}$ at $932.2 \mathrm{eV}$ was observed for the samples of the all four $\mathrm{pHs}$. The relative photoelectron signal intensity to $\mathrm{pH} 2$ and $\mathrm{pH} 8$ samples compared to $\mathrm{pH} 4$ and $\mathrm{pH} 6$ indicate that signals possibly respond not only from $\mathrm{Cu}_{2} \mathrm{O}$ on the surface, but also from the metal substrate of the selective layer.

XPS spectrum analysis shows additional peaks at $933.5 \mathrm{eV}$ and $934.5 \mathrm{eV}$ for samples immersed in a slurry with $\mathrm{pH} 2$ and $\mathrm{pH}$ 8. The selective layer copper in $\mathrm{CuO}$ and $\mathrm{Cu}_{2} \mathrm{O}$ have $\mathrm{BE}$ values of about $933.4 \mathrm{eV}$ and $934.5 \mathrm{eV}$, respectively [35,44]. CuO signals can be identified clearly for the sample of $\mathrm{pH} 8$. These results were further confirmed in the selective layer copper by Auger electron spectroscopy (AES), as shown in Figure 4b.

Figure 5 shows the SEM micrographs of the selective layer surface, obtained in solutions with different $\mathrm{pH}$ values after 30 min of immersion. 

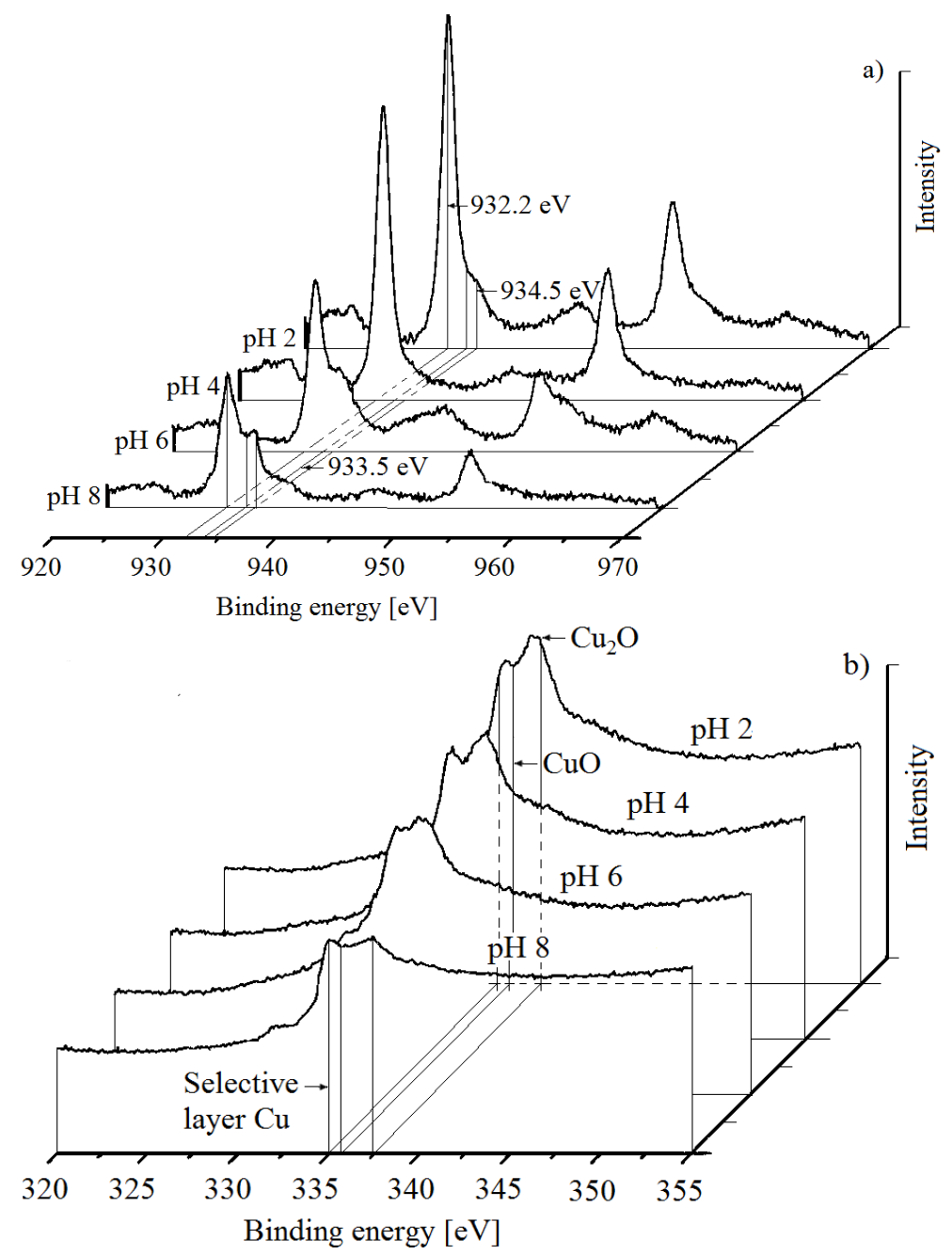

Figure 4. Selective layer copper XPS (a) and AES spectra (b) of $\mathrm{Cu}_{2} \mathrm{O}$ films formed in solutions with $5.5 \% \mathrm{H}_{2} \mathrm{O}_{2}$ at different $\mathrm{pHs}$ after $30 \mathrm{~min}$ of immersion.

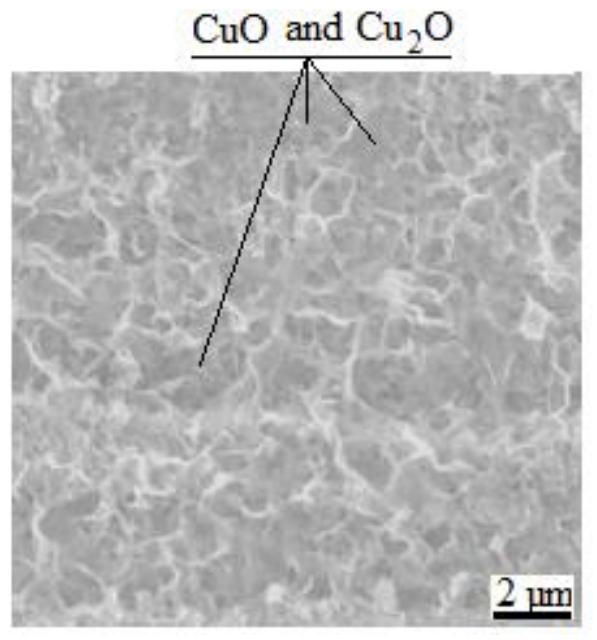

(a)

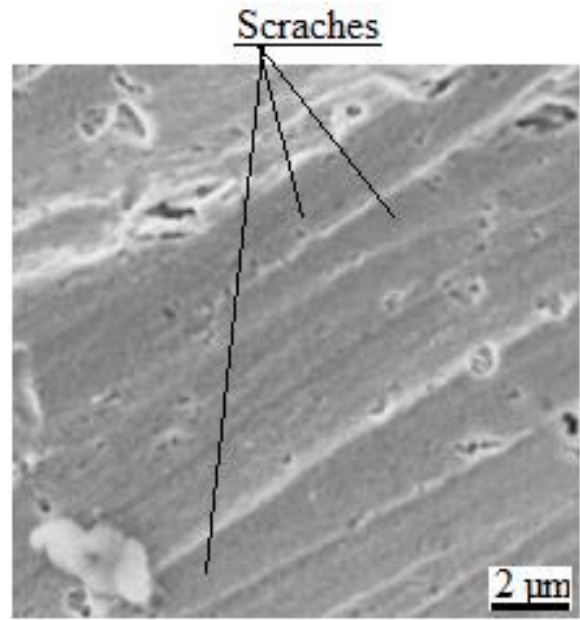

(b)

Figure 5. Cont. 


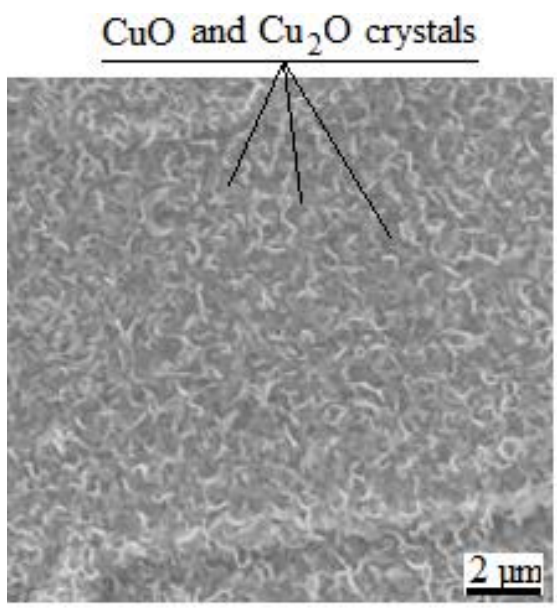

(c)

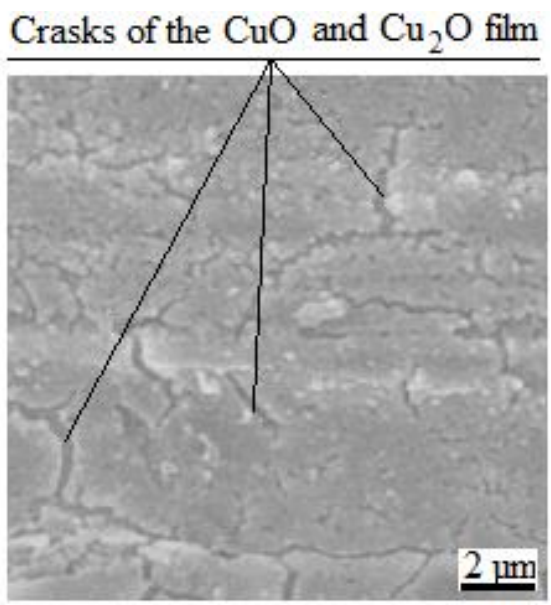

(d)

Figure 5. SEM micrographs for the selective layer surface formed in solutions with $5.5 \% \mathrm{H}_{2} \mathrm{O}_{2}$ at various $\mathrm{pH}$ after 30 min of immersion: (a) $\mathrm{pH}$ 2, (b) $\mathrm{pH} 4,9$ (c) $\mathrm{pH}$ 6, and (d) $\mathrm{pH} 8$.

Figure 5a shows the selective layer surface morphology, obtained in $\mathrm{pH} 2$ solution. The surface morphology indicates a strong etching reaction and the surface was coated with a discontinuous layer of amorphous corrosion products, which are $\mathrm{Cu}_{2} \mathrm{O}$ and $\mathrm{CuO}$, according to XPS analysis. In this situation, $\mathrm{Cu}$ dominates the selective layer so that a higher MRR through CMP was obtained. Figure $5 \mathrm{~b}$ shows the selective layer surface morphology obtained in solution at $\mathrm{pH} 4$. Polishing scratches on the substrate surface could be seen in the micrograph even after a $30 \mathrm{~min}$ immersion, indicating that the layer formation rate is quite low. This is also confirmed by XPS results. Figure $5 \mathrm{c}$ shows the surface morphology of the selective layer obtained in solution with $\mathrm{pH}$ 6. The whole surface was covered with $\mathrm{CuO}$ and $\mathrm{Cu}_{2} \mathrm{O}$ crystals. This layer was porous, but compact, and thus protective. Since the $\mathrm{CuO}$ oxide film is much tougher than the selective layer [1], a relatively lower MRR through CMP was observed. Figure $5 \mathrm{~d}$ shows the surface morphology of the selective layer obtained in a solution at $\mathrm{pH} 8$. A much thicker film formed on the substrate surface can be observed, but it is slightly anchored and oxide film cracks are seen observed everywhere. It can, therefore, be easier to remove it by CMP.

The study was conducted at a constant $\mathrm{H}_{2} \mathrm{O}_{2}$ concentration. In order to observe the slurry $\mathrm{pH}$ effects, the MRR and ER of the selective layer were measured as a function of $\mathrm{pH}$ at $5.5 \mathrm{vol} \% \mathrm{H}_{2} \mathrm{O}_{2}$ concentration. Figure 6 shows that the selective layer MRR and ER at $5.5 \mathrm{vol} \% \mathrm{H}_{2} \mathrm{O}_{2}$ concentration in the slurry decrease with increasing $\mathrm{pH}$.

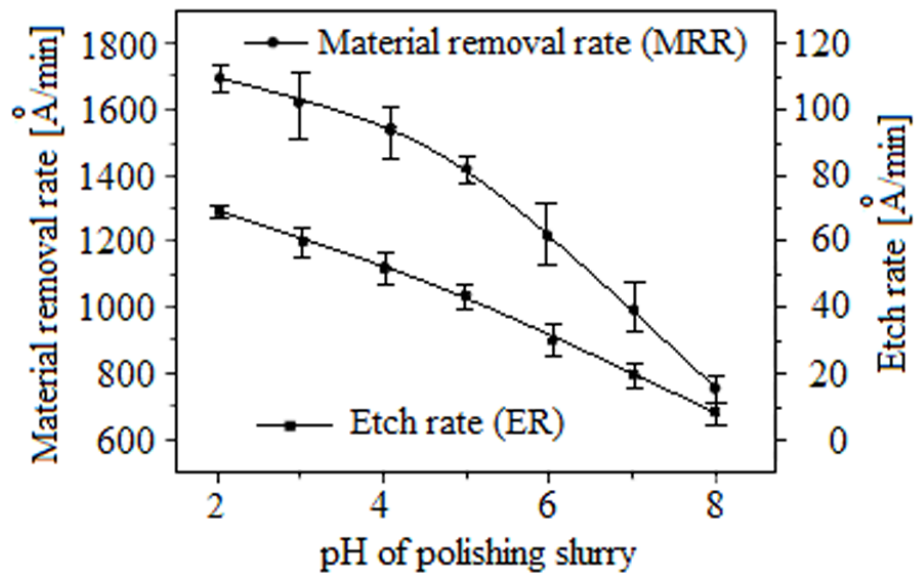

Figure 6. Material removal rate (MRR) and etch rate (ER) vs. $\mathrm{pH}$ at $5.5 \mathrm{vol} \% \mathrm{H}_{2} \mathrm{O}_{2}$ slurry. 
The growth of the $\mathrm{Cu}_{2} \mathrm{O}$ AES peak (see Figure $4 \mathrm{~b}$, where $\mathrm{BE} 337 \mathrm{eV}$ ) with increasing $\mathrm{pH}$ is demonstrated by the fact that there is a larger amount of $\mathrm{Cu}_{2} \mathrm{O}$ on the surface at higher $\mathrm{pH}$ values. The higher amount of $\mathrm{Cu}_{2} \mathrm{O}$ protects (passivates) the metal surface with the selective layer and reduces the oxidation rate of the metallic selective layer at higher $\mathrm{pH}$ values. The presence of these cupric oxides $\left(\mathrm{Cu}_{2} \mathrm{O}, \mathrm{CuO}\right)$ is indicated by the Auger lines at $\mathrm{BE} 934.5 \mathrm{eV}$, as seen in the spectrum in Figure $4 \mathrm{a}$.

The MRR behavior in Figure 6 can be explained by the $\mathrm{pH}$-induced effects. At $5.5 \mathrm{vol} \% \mathrm{H}_{2} \mathrm{O}_{2}$ concentrations, a $\mathrm{CuO}$ film is present on the metallic selective layer surface during polishing. In this case, we note that the MRR decreases with increasing $\mathrm{pH}$ due to decreased $\mathrm{CuO}$ solubility, possibly limited by the solubility of $\mathrm{CuO}$ film that forms on the selective layer metallic surface, during CMP.

\subsection{Slurry Nanoparticle Size Distribution}

To obtain an optimum polishing performance with minimal surface deformations, it is necessary to use mono-modified nanoparticles in the CMP slurries [35]. However, in practice, there may be nanoparticles of larger size in the slurries due to insufficient filtration (hard nanoparticles), or primary slurry nanoparticles due to poor stability (soft nanoparticles). The presence of different size nanoparticles in the CMP slurries unevenly distributes the load applied by the polisher head on the abrasive particles, resulting in surface deformations [32,37]. Although the presence of hard nanoparticles was suspected of causing major surface deformations [32,35,37], the polishing tests made it possible to establish degradation detection limits to check planarization performances. Surface analysis of selective layer wafers polished with hard nanoparticles in the slurry showed an increased surface roughness and several relative surface deformations, compared to baseline polishing, as shown in the AFM images from Figure 7a,b. In addition, significant modifications were detected in the presence of these nanoparticles and in the MRR response, indicating that measures must be taken to protect the surface quality and also to achieve a suitable MRR, by removing them from the slurry.

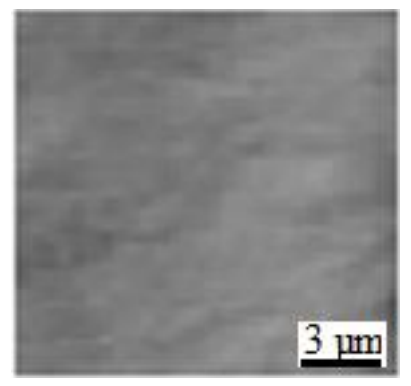

(a)

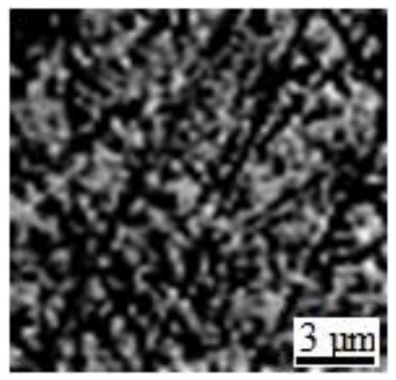

(b)

Figure 7. Surface response quality of the selective layer wafers polished with: (a) baseline slurry; (b) hard nanoparticles in slurry and $1 \mathrm{wt} \% 250 \mathrm{~nm}$ nanoparticles.

To remove larger nanoparticles, a filtration of CMP slurries is usually conducted. Nevertheless, even after filtering of the slurries, defects are often observed on the polished surfaces and may be higher than expected [44]. As a result, there is a suspicion that some of the defects may be created by the agglomeration of nanoparticles formed during the CMP process. These observations indicate that CMP slurries must remain stable during polishing to achieve optimal planarization performances.

\subsection{Stabilization of CMP Slurries}

In the planarization process, the CMP slurry has to be the stabilized in the presence of reactive additives and under extreme conditions of $\mathrm{pH}$, pressure, temperature, and ionic strength. For the stabilization of the nanoparticles a surfactant is used at the solid-liquid interface [16,44-50] because the presence of surfactants allows lubrication between the abrasive and the surface to be polished [50]. 
Thus, friction forces can decrease, resulting in reduced MRR in the presence of the surfactants. The result was that the surface quality was optimal, with the roughness and deformation of the selective layer surface being minimal. Therefore, this emphasizes the importance of nanoparticle-substrate interactions along with the nanoparticle-nanoparticle interactions to optimize the CMP process.

To do this, it was necessary to calculate the applied force on a single abrasive nanoparticle during polishing. This value was estimated to be $100-1000 \mathrm{nN}$ for a $200 \mathrm{~nm}$ nanoparticle following the method used in [51,52] and was in line with the modeling values from the literature [5,10-12,14,51,52]. The use of surfactants showed a nonlinear behavior of the lateral forces, observing a normal force, for $250 \mathrm{~nm}$ nanoparticles, as shown in Figure 8.

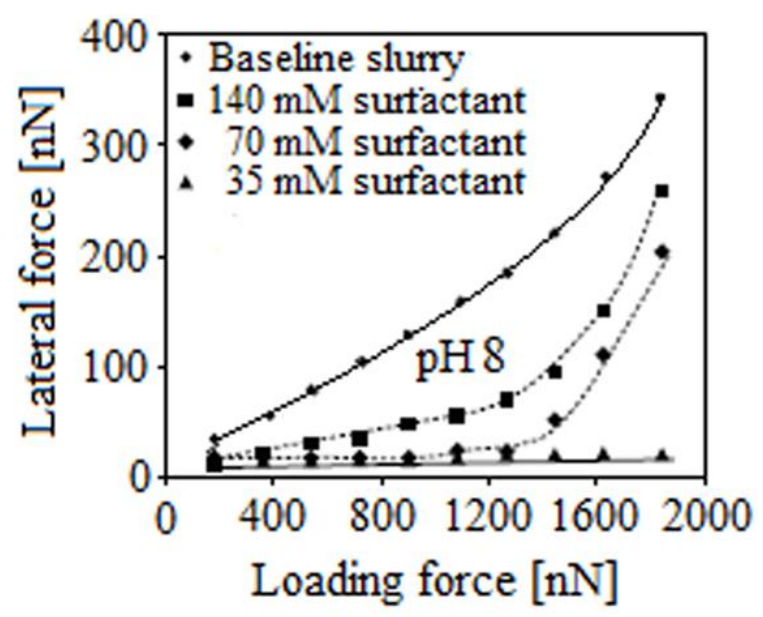

Figure 8. AFM friction force measurements on a selective layer wafer with $250 \mathrm{~nm}$ nanoparticles attached to the tip. Note: Slurries contain surfactants at 35, 70, and $140 \mathrm{mM}$ concentrations at $\mathrm{pH} 8$.

Although the MRR values were low compared to the baseline, this approach allowed a new method to determine the friction forces occurring in the CMP process. Several in situ studies of the friction force response and nanoparticle-substrate friction simulations with AFM for slurries with added surfactant have proved that the adhesion strength of the surfactant and slurry chemistry (composition, $\mathrm{pH}$, ionic strength, and surfactant) can be adapted to provide a sufficient frictional force obtaining an optimal planarization (polishing) performance [51,52]. Hence, the effect of surfactant concentration on stabilization ability of the CMP slurry revealed an optimal concentration range for a certain surfactant. However, by use of a surfactant in the CMP slurry, the surface quality was improved. Therefore, surfactants can be used to stabilize nanoparticles in a CMP slurry, to modify the interactions between nanoparticles, and between nanoparticles and the substrate, during CMP to optimize the process.

\section{Conclusions}

The MRR of the selective layer during CMP or etching is influenced by the presence of selective layer oxides on the surface.

Surface analysis revealed the presence of $\mathrm{Cu}_{2} \mathrm{O}$ on the selective layer surface after immersing selective layer samples in a slurry with different $\mathrm{pHs}$ containing $\mathrm{H}_{2} \mathrm{O}_{2}$.

The presence of the $\mathrm{Cu}_{2} \mathrm{O}$ film reduced the ER of the selective layer. Surface analysis also revealed the presence of $\mathrm{CuO}$ on the selective layer metallic surface. Corrosion products formed on the selective layer surface were found to be responsible for MRR through CMP.

MRR through CMP and ER of the selective layer in slurries with $5.5 \mathrm{vol} \% \mathrm{H}_{2} \mathrm{O}_{2}$ have been shown to vary with $\mathrm{pH}$. When the $\mathrm{pH}$ of the slurry was varied, the polishing rate decreased with increasing $\mathrm{pH}$ at constant $\mathrm{H}_{2} \mathrm{O}_{2}$ concentrations. 
The MRR of the selective layer during CMP for the slurry used in this paper appears to be determined by the oxidation rate of the metallic selective layer and by the solubility of a $\mathrm{Cu}_{2} \mathrm{O}$ or $\mathrm{CuO}$ film.

In the CMP process, the slurry plays an important role in the process performance and should be closely monitored for optimal results. Slurry chemistry should be tailored to contain no hard particles or soft particles in order not to deteriorate the surface quality and lead to inconsistent MRRs.

For an effective planarization, MRR must be optimal and surface defects must be minimal. In order to optimize selective layer CMP, it is necessary to control the chemical and mechanical interactions at the interface between the slurry and selective layer surface, the slurry chemistry, the properties, and the stability of the abrasive nanoparticles, respectively, leading to a deeper understanding of MRR during the planarization process and the specific role of each chemical constituent in the slurry. Therefore, the chemical state of the selective layer surface and the $\mathrm{pH}$ of the slurries play a very important role in the selective layer CMP removal process, and $\mathrm{H}_{2} \mathrm{O}_{2}$ is the most common oxidizer used in the CMP slurry.

By using surfactants at the solid-liquid interface to stabilize the slurry in extreme conditions, the CMP process is improved with optimal effects on the surface quality (minimal roughness and deformations).

For the CMP process to be effective, the friction state at the interface must also be taken into account by measuring the friction force due to the impact of chemical-mechanical, inter-particle, and pad-nanoparticle-substrate interactions.

Acknowledgments: We would like to express the sincere gratitude of the technicians of the Department of Machine Elements and Tribology (DME\&T) for the support in the realization of the metal pattern wafer with the selective layer in the workshop and the laboratories of the department, from which samples cleaved for experiments.

Author Contributions: Filip Ilie and George Ipate conceived and designed the experiments; Filip Ilie and George Ipate performed the experiments; Filip Ilie analyzed the data; George Ipate contributed with materials, and prepared solutions and the analysis tools; and Filip Ilie wrote the paper.

Conflicts of Interest: The authors declare no conflict of interest.

\section{References}

1. Ilie, F. Studytribological of Thin Superficial Layers Formed in the Friction Couples Through Selective Transfer; Technical Publishing House: Bucharest, Romania, 2002.

2. Ilie, F.; Tita, C. Comparative analysis of tribological performances of materials that can achieve thin layers from selective transfer. J. BalkanicalTribol. Assoc. 2006, 12, 404-411.

3. Garkunov, D.N. Tribotechnology (Wear and Non-Wear); Publishing House MSKHA: Moscow, Russia, 2001. (In Russian)

4. Ilie, F. Tribochemical interaction between nanoparticles and surfaces of selective layer during chemical mechanical polishing. J. Nanopart. Res. 2013, 15, 1997. [CrossRef]

5. Ilie, F. Models of nanoparticles movement, collision, and friction in chemical mechanical polishing (CMP). J. Nanopart. Res. 2012, 14, 752-759. [CrossRef]

6. Armini, S.; Whelan, C.M.; Moinpour, M.; Maex, K. Copper CMP with Composite Polymer Core-Silica Shell Abrasives: A Defectivity Study. J. Electrochem. Soc. 2009, 156, H18-H26. [CrossRef]

7. Nolan, L.; Cadien, K. Chemical Mechanical Polish for Nanotechnology. In Nanolubrification; Stepanova, M., Dew, S., Eds.; Springer: Vienna, NY, USA, 2012.

8. Guo, D.; Xie, G.; Luo, J. Mechanical properties of nanoparticles: Basics and applications. J. Phys. D 2014, 47, 1-25. [CrossRef]

9. Dubin, V.M. Copper Electroplating for On-Chip Metalization. In Advanced Interconnects for ULSI Technology; Baklanov, M.R., Ho, S., Zschech, E., Eds.; Jhon Wiley and Sons Ltd.: West Sussex, UK, 2012.

10. Luo, J; Dornfeld, D.A. Material removal mechanism in chemical mechanical polishing: Theory and modeling. IEEE Trans. Semicond. Manuf. 2001, 14, 112-133. 
11. Gopal, T.J.; Talbot, J.B. Use of Slurry Colloidal Behavior in Modeling of Material Removal Rates for copper MP. J. Electrochem. Soc. 2007, 154, H507-H512. [CrossRef]

12. Ihnfeldt, R.; Talbot, J.B. Modeling of Copper CMP Using the Colloidal Behavior of an Alumina Slurry with Copper Nanoparticles. J. Electrochem. Soc. 2007, 154, H1018-H1026. [CrossRef]

13. Pirayesh, H.; Cadien, K. The Effect of Slurry Properties on the CMP Removal Rate of Boron Doped Polysilicon. ECS J. Solid State Sci. Technol. 2016, 5, P233-P238. [CrossRef]

14. Ihnfeldt, R.; Talbot, J.B. The Effects of Copper CMP Slurry Chemistry on the Colloidal Behavior of Alumina Abrasives. J. Electrochem. Soc. 2006, 153, G948-G955. [CrossRef]

15. Ihnfeldt, R.; Talbot, J.B. Modeling Material Removal Rates for Copper CMP Using Copper Nanohardness and Etch Rates. J. Electrochem. Soc. 2008, 155, H582-H588. [CrossRef]

16. Luo, J.; Dornfeld, D.A. Effects of Abrasive Size Distribution in Chemical Mechanical Planarization: Modeling and Verification. IEEE Trans. Semicond. Manuf. 2003, 16, 469.

17. Chen, H.; Guo, D.; Xie, G.; Pan, G. Mechanical model of nanoparticles for material removal in chemical mechanical polishing process. Friction 2016, 4, 153-164. [CrossRef]

18. Banerjee, G. Chemical Mechanical Planarization for Cu-Low-k Integration. In Advanced Interconnects for ULSI Technology; Baklanov, M.R., Ho, S., Zschech, E., Eds.; Jhon Wiley and Sons Ltd.: West Sussex, UK, 2012.

19. Choi, S.; Doyle, F.M.; Dornfeld, D.A. Material Removal Mechanism during Copper Chemical Mechanical Planarization Based on Nano-Scale Material Behavior. ECS J. Solid State Sci. Technol. 2017, 6, P235-P242. [CrossRef]

20. Basim, G.B.; Moudgil, B.M. Effect of Soft Agglomerates on CMP Slurry Performance. J. Colloid Interface Sci. 2002, 256, 137-142. [CrossRef]

21. Brahma, N.A. Effects of Slurry Chemistry on the Rate of Agglomeration of Alumina Nanoparticles for Chemical Mechanical Planarization. Ph.D. Thesis, University of California, San Diego, CA, USA, 2013.

22. Jindal, A.; Babu, S.V. Effect of pH on CMP of Copper and Tantalum. J. Electrochem. Soc. 2004, 151, G709-G716. [CrossRef]

23. Du, T.; Desai, V. The pH Effect on Chemical Mechanical Planarization of Copper. Proc. MRS 2003, 767. [CrossRef]

24. Wang, Y.G.; Zhang, L.C.; Biddut, A. Chemical effect on the material removal rate in the CMP of silicon wafers. Wear 2011, 270, 312-316. [CrossRef]

25. Bielman, M. 1998. Chemical Mechanical Polishing of Tungsten. Master's Thesis, University of Florida, Gainesville, FL, USA, 1998.

26. Jiang, L.; He, Y.; Yang, Y.; Luo, J. Chemical Mechanical Polishing of Stainless Steel as Solar Cell Substrate. ECS J. Solid State Sci. Technol. 2015, 4, P162-P170. [CrossRef]

27. Kao, M.J.; Hsu, F.C.; Peng, D.X. Synthesis and Characterization of $\mathrm{SiO}_{2}$ Nanoparticles and Their Efficacy in Chemical Mechanical Polishing Steel Substrate. Adv. Mater. Sci. Eng. 2014, 2014, 691967.

28. Deshpande, S.; Kuiry, S.C.; Klimov, M.; Obeng, Y.; Seal, S. Chemical Mechanical Planarization of Copper: Role of Oxidants and Inhibitors. J. Electrochem. Soc. 2004, 151, G788-G794. [CrossRef]

29. Eom, D.H.; Kim, I.K.; Han, J.H.; Park, J.G. The Effect of Hydrogen Peroxide in a Citric Acid Based Copper Slurry on Cu Polishing. J. Electrochem. Soc. 2007, 154, D38-D44. [CrossRef]

30. Kim, I.K.; Kang, Y.J.; Kim, T.G.; Park, J.G. Effect of Corrosion Inhibitor, Benzotriazole, in Cu Slurry on Cu Polishing. Jpn. J. Appl. Phys. 2008, 47, 108-112. [CrossRef]

31. Aksu, S.; Wang, L.; Doyle, F. Effect of Hydrogen Peroxide on Oxidation of Copper in CMP Slurries Containing Glycine. J. Electrochem. Soc. 2003, 150, G718. [CrossRef]

32. Du, T.; Vijayakumar, A.; Desai, V. Effect of hydrogen peroxide on oxidation of copper in CMP slurries containing glycine and $\mathrm{Cu}$ ions. Electrochim. Acta 2004, 49, 4505-4512. [CrossRef]

33. Jiang, L.; He, Y.; Liang, H.; Li, Y.; Luo, J. Effect of Potassium Ions on Tantalum Chemical Mechanical Polishing in $\mathrm{H}_{2} \mathrm{O}_{2}$-Based Alkaline Slurries. ECS J. Solid State Sci. Technol. 2016, 5, P100-P111. [CrossRef]

34. Xie, Y.; Bhushan, B. Effects of particle size, polishing pad and contact pressure in free abrasive polishing. Wear 1996, 200, 281. [CrossRef]

35. Cook, L.M. Chemical Mechanical Planarization of Microelectronic Materials. J. Non-Cryst. Solids. 1990, 120, 152. [CrossRef]

36. Brown, N.J.; Baker, P.C.; Maney, R.T. A new model for surface roughness evolution in the Chemical Mechanical Polishing Process. Proc. SPIE 1981, 306, 42. 
37. Trogolo, J.A.; Rajan, K. Near surface modification of the silica structure induced by chemical/mechanical polishing. J. Mater. Sci. 1994, 29, 4554-4558. [CrossRef]

38. Basim, G.B.; Adler, J.J.; Mahajan, U.; Singh, R.K. Effect of particle size of chemical mechanical polishing slurries for enhanced polishing with minimal defects. J. Electrochem. Soc. 2000, 147, 3523-3528. [CrossRef]

39. Sivaram, S.; Bath, M.H.M.; Lee, E.; Leggett, R.; Tolles, R. Chemical Mechanical Polishing of Inter-level Dielectrics: Models for Removal Rate and Planarity. In MRS Proceedings; Cambridge University Press: Cambridge, UK, 1992.

40. Basim, G.B.; Vakarelski, I.U.; Brown, S.; Moudgil, B.M. Strategies for the Optimization of Chemical Mechanical Polishing (CMP) Slurries. J. Dispers. Sci. Technol. 2003, 24, 499-515. [CrossRef]

41. Xu, X.; Luo, J.; Lu, X.; Zhang, C. Effect of Nanoparticle Impact on Material Removal. J. Tribol. Trans. 2008, 51, 718-722. [CrossRef]

42. Scarfo, A.M.; Manno, V.P.; Rogers, C.B.; Anjur, S.; Moinpour, M. In-Situ Measurement of Pressure and Friction During CMP of Contoured Wafers. J. Electrochem. Soc. 2005, 152, G477-G481. [CrossRef]

43. Khanna, A.J. 2010. Quantification of Particle Agglomeration during Chemical Mechanical Polishing of Metals and Dielectrics. Ph.D. Thesis, University of Florida, Gainesville, FL, USA, 2010.

44. Mcintyre, N.S.; Sunder, S.; Shoesmith, D.W.; Stanchell, F.W. Chemical information from XPS-Applications to the analysis of electrode surfaces. J. Vac. Sci. Technol. 1981, 18, 714. [CrossRef]

45. Colic, M.; Fuerstenau, D.W. Influence of the dielectric constant of the media on oxide stability in surfactant solutions. Langmuir 1997, 13, 6644. [CrossRef]

46. Solomon, M.J.; Saeki, T.; Wan, M.; Scales, P.J.; Boger, D.V.; Usui, H. Effect of adsorbed surfactants on the rheology of colloidal zirconia suspensions. Langmuir 1999, 15, 20. [CrossRef]

47. Koopal, L.K.; Goloub, T.; deKaiser, A.; Sidorova, M.P. The effect of cationic surfactants on wetting, colloid stability and flotation of silica. Colloids Surf. 1999, 151, 15. [CrossRef]

48. Bremmel, K.E.; Jameson, G.J.; Biggs, S. Adsorption of ionic surfactants in particulate system: Flotation, stability, and interaction forces. Colloids Surf. 1999, 146, 755. [CrossRef]

49. Evanko, C.R.; Dzombak, D.A.; Novak, J.W. Influence of surfactant addition on the stability of concentrated alumina dispersions in water. Colloids Surf. 1996, 110, 219. [CrossRef]

50. Adler, J.J.; Singh, P.K.; Patist, A.; Rabinovich, Y.I.; Shah, D.O.; Moudgil, B.M. Correlation of particulate dispersion stability with the strength of self-assembled surfactant films. Langmuir 2000, 16, 7255-7262. [CrossRef]

51. Basim, G.B.; Vakarelski, I.U.; Moudgil, B.M. Role of interaction forces in controlling the stability and polishing performance of CMP slurries. J. Colloid Interface Sci. 2003, 263, 506-515. [CrossRef]

52. Bozkaya, D.; Müftü, S. Effects of Surface Forces on Material Removal Rate in Chemical Mechanical Planarization. J. Electrochem. Soc. 2010, 157, H287-H296. [CrossRef] 